\title{
Non-stationary drivers of polar sea ice area
}

\author{
Reginald R. Muskett
}

Geophysical Institute, University of Alaska Fairbanks, Fairbanks, USA; rmuskett@gi.alaska.edu

Received 12 February 2011; revised 20 March 2011; accepted 18 April 2011.

\section{ABSTRACT}

From 2002 through 2008 the secular rate of decreasing sea ice area in the northern hemisphere accelerated by a factor of 18 , whereas the secular rate of increasing sea ice area in the southern hemisphere accelerated by a factor of 16, relative to the rates from 1978 through 2007. These were derived from the daily sea ice area retrieved from the Scanning Multi-channel Microwave Radiometer - Special Sensor Microwave/Imager and the Advanced Microwave Scanning Radiometer for the Earth Observation System. The "annual" cycle of northern and southern sea ice areas, the number of days between maxima and minima is 372.4 , on average, a frequency modulation, with a recurrence interval of 61.7 years. Significant spectral power occurs at the quasi-4-day through 120-day frequencies. The frequency content and modulation of the daily time series' are consistent inter-monthly to inter-seasonal frequencies of solar irradiance, atmospheric-oceanic Rossby waves, length-ofday, and polar motion. This suggests conservation of angular momentum of the atmosphere sea-ice - ocean system. The near 60 -year modulation and analysis of the detrended daily time series of the Arctic and Antarctic sea ice areas suggest the accelerations shown by the secular trends are relatively short-lived and reversible within an interval of one-quarter (15-years) to one-half (30-years) of the modulation period.

Keywords: Hemispheric Sea-Ice Area Changes; Trends; Frequency Modulations; Physical Drivers

\section{INTRODUCTION}

The sea ice areas at the polar oceans serve a vital function through surface albedo in the energy balance and climate system of Earth [1-5]. Forcing on sea ice area (growth and decay) comes from solar radiation, infrared radiation under cloudy-sky conditions, ocean kinematics and heat transfer, and surface winds acting on daily, seasonal, annual, inter-annual, decadal and longer time scales. Satellite datasets of the daily sea ice area of the northern and southern hemispheres can be assessed for secular trends and variations [6-10]. Figure 1 shows the northern (Arctic, left) and southern hemisphere (Antarctic, right) sea ice area, on 17 August 2008, seen in colorized concentration per pixel from satellite observations.

The annual growth, decay and net changes in polar sea ice areas and the hemispheric asymmetry derived by satellite-borne passive microwave sensors were first described by Cavalieri et al. [6]. These data are available from the National Snow and Ice Data Canter, Univ. Colorado, as the NASA TEAM from late 1978 through end of 2007 and the BOOTSTRAP from late 1978 through end of 2006. The algorithms used in the retrieval of sea ice area and area-extent use surface brightness temperatures to derive grid cells with sea ice concentrations above $15 \%$. In this fashion, sea ice area-extent is defined as the cumulative area of grid cells with concentration of sea ice greater than $15 \%$ per gridcell, relative to water, and sea ice area is defined as the cumulative area of sea ice with $100 \%$ sea ice concentration per grid cell (a more conservative estimator). The algorithmic measurement and calibrations, for the scanning multi-channel microwave radiometer (SMMR) which was flown on Nimbus

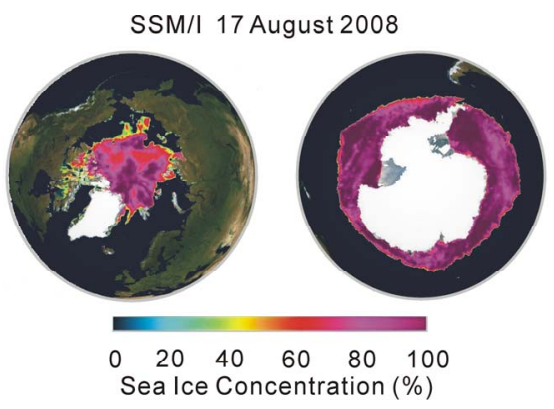

Figure 1. Northern (left) and southern hemisphere (right) sea ice areas on 17 August 2008. Sea ice concentration images were provided by the Polar Research Group, Department of Atmospheric Sciences, University of Illinois, Urbana-Champaign. 
7 from late 1978 through late 1987, and the Defense Meteorological Satellite Program special sensor microwave/imager (SSM/I) which was flown on satellites F8, F11, F13 and F15 (F13 is till operational and F15 recently experienced anomalous behavior) began from mid-1987 and current is described in Cavalieri et al. [7]. In this investigation we will use the daily sea ice area (not extent) from the NASA TEAM algorithm, from the northern (Arctic) and southern hemisphere (Antarctic) since it covers the longer time interval from October 1978 through the end of December 2007. The daily summation of the hemispheres gives the daily global sea ice area. The SMMR portion of the dataset with missing values and the early portion of the SSM/I record from 3 December through 12 January with missing values, were filled by linear interpolation.

In addition to the SMMR-SSM/I time series of sea ice area we use daily sea ice area data from the Advanced Microwave Scanning Radiometer for the Earth Observation System (AMSR-E), derived through an algorithm developed by scientists Institute of Oceanography, University of Hamburg, Germany [11]. This sensor, flown on the NASA-Aqua satellite, provides a dataset that covers the period from mid-2002 through 2008, for comparison with the SMMR-SSM/I data. The AMSR-E sensor differs from the SSM/I passive-microwave sensor in having more brightness temperature channels and a greater spatial resolution, 6-by-4 km at the primary $89 \mathrm{GHz}$ channel. Comparisons of retrieved sea ice area by these algorithms and ship-borne estimates showed good agreement [11]. A few missing day-values of the AMSR-E time series were filled by linear interpolation.

Figure 2 illustrates the daily sea ice area time series, the polar sea ice area (sum of the same-day Arctic and Antarctic sea ice areas), from SMMR-SSM/I from late1978 through 2007 (top) and from AMSR-E from late2002 through 2008 (bottom). The curious shape of the sinusoidal is due to the day of the Arctic and Antarctic minima and maxima which do not coincide. The calendar-day occurrence of minimum and maximum varies over the length of the time series. The green lines signify the global area maxima and minima of the daily time series for comparison. The global sea ice area attained an upper-bound maximum in 1987 (top, solid green line). Minima after 1997 (top, dashed green line) have been variable, though decreasing since 2005 (bottom, dashed green line).

Previous studies of trends and variations of Arctic and Antarctic sea ice extents and areas utilized the same SMMR-SSM/I daily satellite datasets although over different total-year lengths with monthly and annual averaging and time-domain and frequency-domain smoothing [6-8]. Uncorrelated inter-annual periodicities that
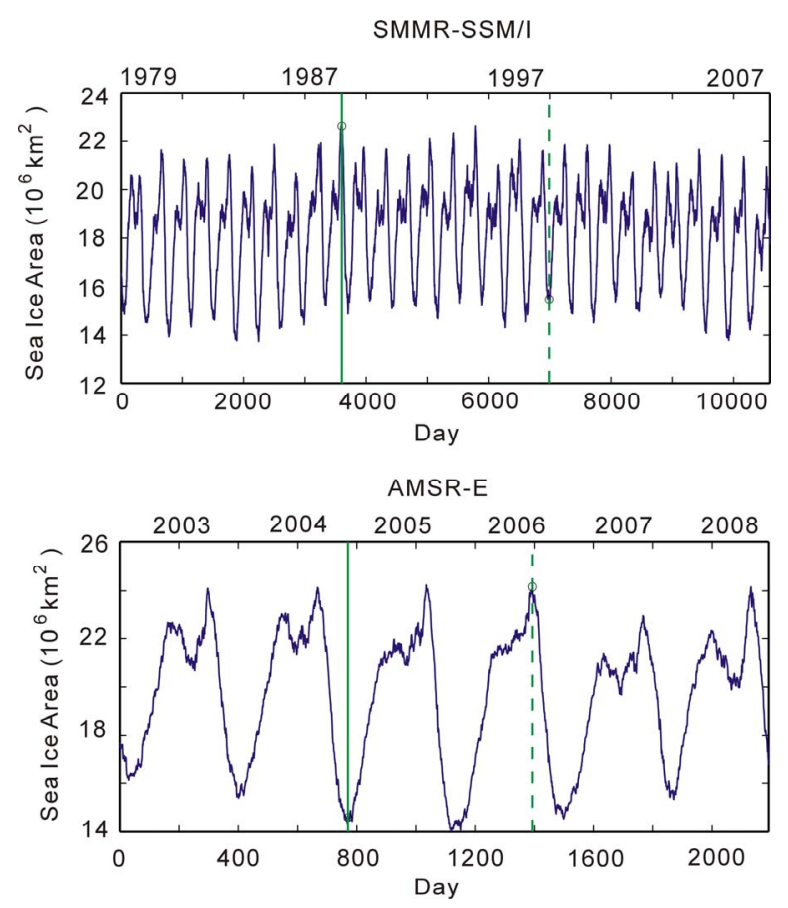

Figure 2. Daily time series of polar sea ice area from SMMRSSM/I NASA Team algorithm. Gaps in the records were filled by linear interpolation.

remained were dominant at 5-year period in the Arctic, and 3-year period in the Antarctic of sea ice extent. Net decadal decrease in the Arctic sea ice extent - area and the increase in Antarctic sea ice extent - area were attributed to increasing atmospheric $\mathrm{CO}_{2}$ concentrations, consistent with results of a global circulation model with gradual $\mathrm{CO}_{2}$ forcing [6-12]. This has again been brought to attention given the anomalous reduction of Arctic Sea ice extent in the summer of 2007, while the Antarctic sea ice extent continues to increase without any noted unusual seasonal changes [11,13,14].

We note the existence of calendar (day-month-year) and averaging (aggregation) effects, which can lead to spurious anomalies and trends; such as the leap-year effect noted in daily/monthly temperature data and many other calendar effects known to financial statistics [15, 16]. Smoothing of data whether in the time-domain or the frequency-domain can be filled with problems associated with introducing bias into the analysis [17]. The SMMR-SSM/I daily sea ice extent and area time series are both seasonal and non-stationary (i.e. the mean and variance change over time, hence time dependent). This has likely lent to reports of citing seemingly conflicting derived trends, magnitudes and polarities $[8,12,18]$. Temporal aggregating of discrete non-stationary time series can lead to aliases, spurious correlations and false- eaks in autoregressive moving average models [19,20]. For these reasons, we will investigate the datasets without 
calendar-based monthly and annual averaging, and without time-domain and frequency domain smoothing or autoregressive moving average techniques [21]. Our approach is to utilize linear regression to identify trends, secular and higher-order, and the Discrete Fast Fourier Transform with zero-padding [22,23]. We then use the secular trends to detrend the daily Arctic, Antarctic and Global time series to investigate their frequency content.

\section{RESULTS}

\subsection{Sea Ice Areas: Means, Standard Deviations and Seasonal Ranges}

Table 1 summarizes sea ice areas, Arctic, Antarctic and Polar, by their means (with uncertainty), standard deviations and seasonal ranges from the daily sea ice area estimates from SMMR-SSM/I from 29 Dec. 1978 through 29 Dec. 2007 and from AMSR-E from 31 Dec. 2002 through 31 Dec. 2008. Comparison shows that the mean Arctic sea ice area decreasing by about 3\%, the mean Antarctic sea ice area increasing by about $16 \%$, and the mean Polar sea ice area is increasing by about $7 \%$. The seasonal range of Arctic sea ice area lowered its minimum by about one million square kilometers and its maximum remained unchanged, on average. The seasonal range of the Antarctic sea ice area, in contrast, raised its maximum by about two million square kilometers and its minimum remained unchanged, on average. The seasonal range of the polar sea ice area raisedboth its minimum and maximum by about one million square kilometers, on average. The standard deviations of the areas show changes of 1\% (Arctic), 14\% (Antarctic) and 30\% (Global), on average, in the comparative time periods.

\subsection{Sea Ice Area Secular Trends and Variations}

The daily sea ice area time series were processed by ordinary least-squares regression to derive secular and quadratic trends. The daily time series were then detrended and processed by the Discrete Fast Fourier Transform (DFFT) to derive the power spectral density. The DFFT was applied on samples of 4096 in three sub-ranges spanning the full-ranges of each SMMR$\mathrm{SM} / \mathrm{I}$ time series, as well as the full-range (10593 samples) with zero-padding to 16384 samples $\left(2^{14}\right)$. Frequency components were the same in all the 4096 subranges, and over the full-range with zero-padding to a $2^{\mathrm{n}}$ multiple. The AMSR-E time series (2192 samples) were zero-padded to 4096 samples. Figures 3, 4 and 5 illustrate the trends (secular and quadratic) of the daily sea ice area time series and the power spectral density (from detrended time series) for the Arctic, Antarctic and Polar, respectively. Table 2 summarizes the secular trends with uncertainties.

Daily Arctic sea ice area has secular decreases of $17998 \pm 3587 \mathrm{~km}^{2} / \mathrm{yr}$ (SMMR-SSM/I) from late-1978 through 2007 and $317277 \pm 37212 \mathrm{~km}^{2} / \mathrm{yr}$ (AMSR-E) from late-2002 through 2008 (Figure 3). Daily Antarctic sea ice area has secular increases of $24311 \pm 5359 \mathrm{~km}^{2} / \mathrm{yr}$ (SMMR-SSM/I) from late-1978 through 2007 and 371 $680 \pm 65789 \mathrm{~km}^{2} / \mathrm{yr}$ (AMSR-E) from late-2002 through 2008 (Figure 4). Daily Polar sea ice area has secular increases of $6133 \pm 2332 \mathrm{~km}^{2} / \mathrm{yr}$ (SMMR-SSM/I) from late-1978 through 2007 and $54404 \pm 33391 \mathrm{~km}^{2} / \mathrm{yr}$ (AMSR-E) from late-2002 through 2008 (Figure 5). The rate of secular-decrease of the daily Arctic sea ice area has increased by a factor of about 18 , from late-2002 through 2008 relative to late-1978 through 2007 (Table 2).

Table 1. Arctic, antarctic and global sea ice area statistics, 1978 through 2008.

\begin{tabular}{|c|c|c|c|}
\hline \multicolumn{4}{|c|}{ SMMR-SSM/I (29 Dec. 1978 through 29 Dec. 2007) Area $\left(\mathrm{km}^{2}\right)$} \\
\hline & Arctic & Antarctic & Polar \\
\hline Mean & $9431838 \pm 30069$ & $8759378 \pm 44911$ & $18191215 \pm 19475$ \\
\hline S.D. & 3094748 & 4622378 & 2004386 \\
\hline Range & $\sim 4$ to $14\left(10^{6}\right)$ & $\sim 2$ to $16\left(10^{6}\right)$ & $\sim 13$ to $23\left(10^{6}\right)$ \\
\hline \multicolumn{4}{|c|}{ AMSR-E (31 Dec. 2002 through 31 Dec. 2008) Area $\left(\mathrm{km}^{2}\right)$} \\
\hline & Arctic & Antarctic & Polar \\
\hline Mean & $9189721 \pm 65515$ & $10458208 \pm 114793$ & $19647928 \pm 57870$ \\
\hline S.D. & 3067316 & 5374473 & 2709399 \\
\hline Range & $\sim 3$ to $14\left(10^{6}\right)$ & $\sim 2$ to $18\left(10^{6}\right)$ & $\sim 14$ to $24\left(10^{6}\right)$ \\
\hline
\end{tabular}



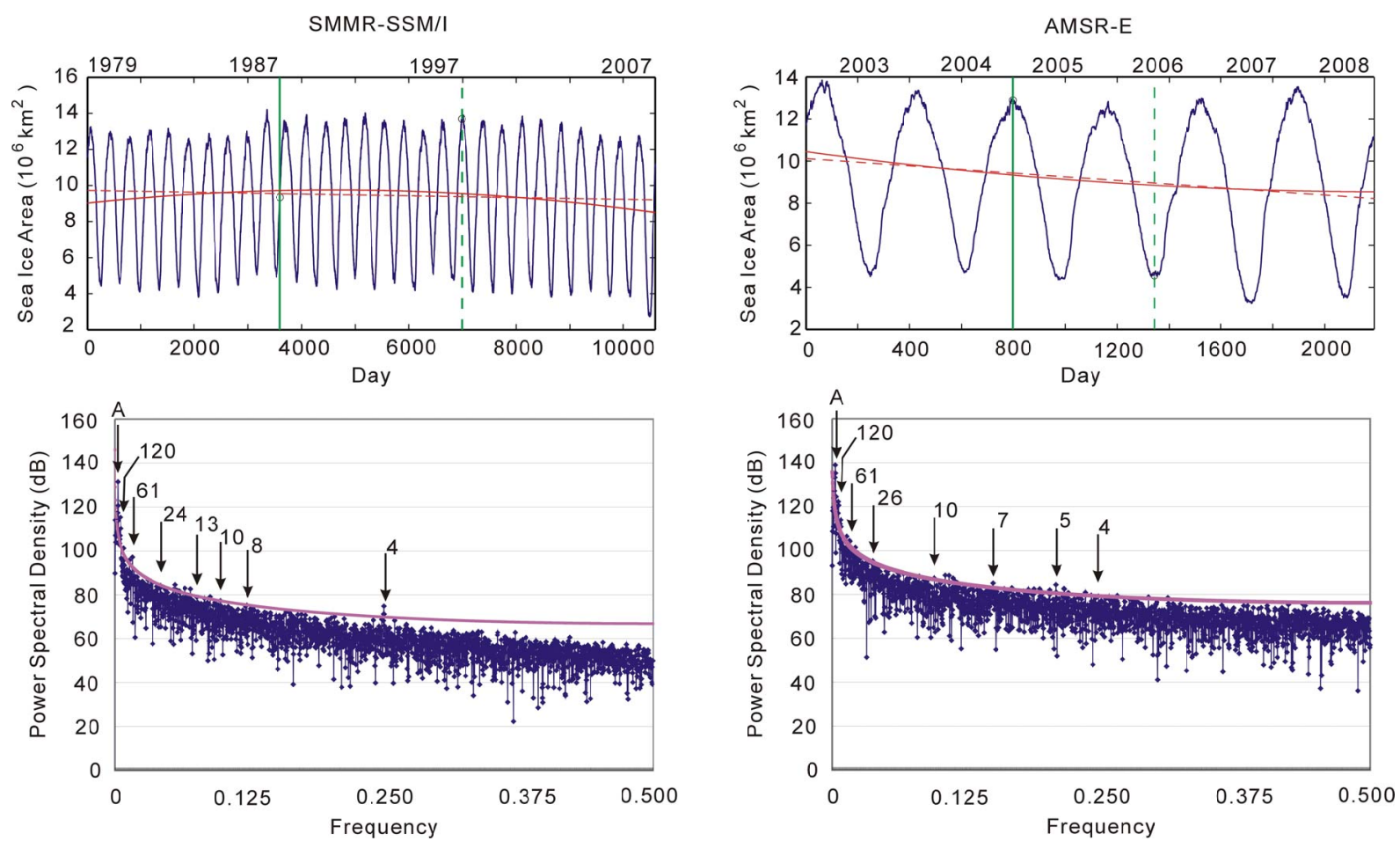

Figure 3. Trends and power density spectra (from detrended series) of the daily Arctic sea ice area. Trends are for secular (dashed red line) and quadratic (solid red line). Numbers in the spectra indicate frequencies with power above the modeled $\chi^{2}$ red noise curve. The "annual" frequency is indicated by the capital letter.
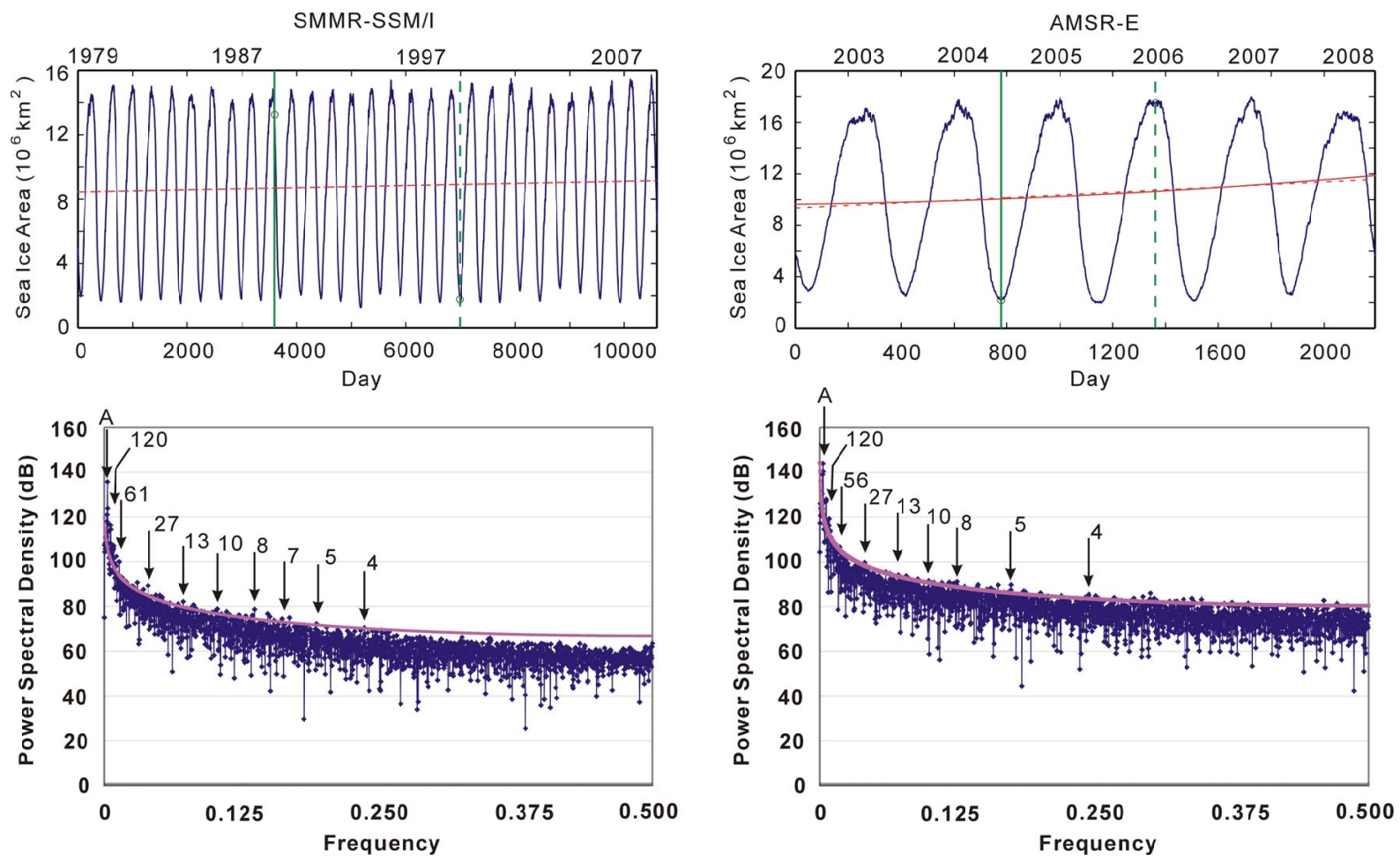

Figure 4. Trends and power density spectra (from detrended series) of the daily Antarctic sea ice area. Trends are for secular (dashed red line) and quadratic (solid red line). Numbers in the spectra indicate frequencies with power above the modeled $\chi^{2}$ red noise curve. The "annual" frequency is indicated by the capital letter. 

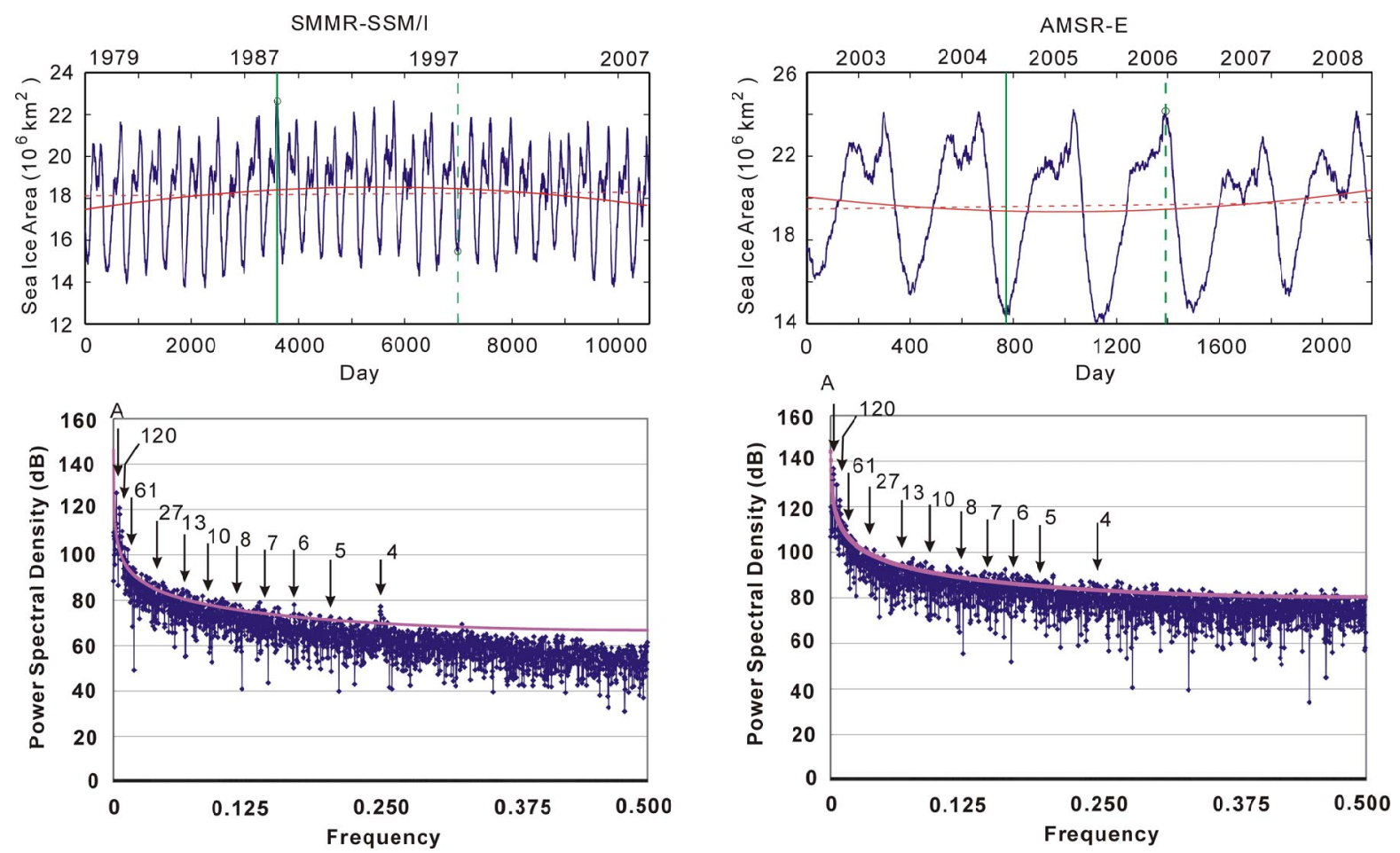

Figure 5. Trends and power density spectra (from detrended series) of the daily Polar (sum of the northern and southern hemispheres) sea ice area. Trends are for secular (dashed red line) and quadratic (solid red line). Numbers in the spectra indicate frequencies with power above the modeled $\chi^{2}$ red noise curve. The "annual" frequency is indicated by the capital letter.

Table 2. Secular trends of Arctic, Antarctic and Polar sea ice area.

\begin{tabular}{|c|c|c|}
\hline \multicolumn{3}{|c|}{ SMMR-SSM/I (29 Dec. 1978 through 29 Dec. 2007) Rates (km²/yr) } \\
\hline Arctic & Antarctic & Polar \\
\hline$-17998 \pm 3587$ & $+24311 \pm 5359$ & $+6133 \pm 2332$ \\
\hline \multicolumn{3}{|c|}{ AMSR-E (31 Dec. 2002 through 31 Dec. 2008) } \\
\hline Arctic & Antarctic & Polar \\
\hline$-317277 \pm 37212$ & $+371680 \pm 65789$ & $+54404 \pm 33391$ \\
\hline
\end{tabular}

By comparison (Table 2), the rate of secular-increase in the daily Antarctic sea ice area has increased by a factor of about 16, comparing the same periods. However in the same comparative periods, the rate of secular-increase in the daily Polar sea ice area has increased by a factor of about 9 (Table 2).

Power spectral density of the detrended series indicated significant, above the modeled $\chi^{2} 99 \%$ confidence level, frequency components. The detrended SMMRSM/I daily Arctic sea ice area series has significant power located at 4, 11, 16, 24, 61, and 120-day frequencies. The detrended SMMR-SMM/I daily Antarctic sea ice area series has significant power located at 4, 5, 10, $16,27,51,61$, and 120-day frequencies. The detrended
AMSR-E daily Arctic sea ice area series has significant power located at 4, 5, 10, 26, 46, 61, and 120-day frequencies. The detrended AMSR-E Antarctic sea ice area series has significant power located at 4, 5, 10, 13, 16, 56, 72, and 120-day frequencies. The detrended SMMRSSM/I and AMSR-E daily Polar sea ice area series contained significant power at the same frequencies as the Arctic and Antarctic sea ice area series. In all the detrended daily time series, SMMR-SSM/I and AMSR-E, the annual cycle for the Arctic, Antarctic and Polar areas was 372.4 days, on average (Figures 3, 4 and 5).

\section{DISCUSSIONS}

Power spectra (Figures 3, 4 and 5) of the detrended daily sea ice area time series show significant power at 4 , $5,10,13,16,27,51,61$ and 120-day frequencies in the Arctic, Antarctic and Polar sea ice areas. These shortterm variations in sea ice area are consistent with the same variations of solar irradiance (total and ultraviolet), Rossby waves in the atmosphere and ocean, length-ofday and polar motion [24-36].

The annual cycle of the SMMR-SSM/I and AMSR-E daily sea ice area time series has a period of 372.4-days, on average. Close inspection of time series by day-count of sea ice area maximum-to-maximum and minimum-tominimum show that the annual cycle varied from 305- 
days (minima) in 1995-96 to 394-days (maxima) in 1989-90, SMMR-SSM/I Arctic sea ice area time series and 333-days (minima) in 2005-06 to 389-days (minima) in 2006-07, AMSR-E Arctic sea ice time series. The Antarctic and Polar sea ice time series show similar variations in the annual cycle day-count ranges spanning minima-to-minima and maxima-to-maxima. This indicates a frequency modulation on the timing of minima and maxima from year to year of the sea ice area, with a recurrence period of 61.7 years; i.e. a sinusoidal forcing with a period on the order of 60 years. The 60 -year modulation of the annual cycle of both hemispheres sea ice areas is consistent with the 60 -year modulation of global air temperature and circulation by the coupled solar irradiance - length-of-day variations [37,38]. The physical basis for coupling this modulation to Polar sea ice area variations would be through conservation of atmospheric-ocean angular momentum $[39,40]$. This is a natural consequence given that sea ice acts as a boundary layer between the atmospheric and ocean momentum fields $[4,41,42]$.

The long-term quadratic trend in the daily SMMRSSM/I Arctic and Polar sea ice area time series and the short-term quadratic trends in the daily AMSR-E Arctic, Antarctic and Polar sea ice area time series suggest periodic forcing acting on the growth and decay of sea ice area. The long-term quadratic trend suggests a forcing on the Arctic sea ice area with a period of 60 -years, consistent with solar irradiation - length-of-day modulation of surface temperatures and atmospheric-ocean circulation. The short-term quadratic trends may themselves be linked to Rossby waves to conserve angular momentum in the coupled atmosphere-sea ice-ocean system of the northern and southern hemispheres.

Secular trends show apparent increases in the rates of Arctic sea ice area decrease, Antarctic sea ice area increase, and Polar sea ice area increase from 2002 through 2008 relative to those from 1978 through 2007 (Table 2). The detrended daily AMSR-E Arctic and Antarctic sea ice area showed steady changes in the magnitudes of the seasonal minima and maxima from late-2002 through 2008 (Figure 6). The Arctic seasonal maxima showed steady increase while the seasonal minima showed decreases. Interestingly the Antarctic seasonal maxima showed decreases and its seasonal minima showed some decreases (Figure 6, bottom). These findings suggest processes operating to moderate the long- term secular trends (Table 2). If these processes continue as linked to the 60-year solar - atmosphere - length-of- day modulation, then the secular trends of decreasing Arctic seas ice area and increasing Antarctic sea ice area could be reversed within as little as 15 to 30 -years, a quarter to one-half period.
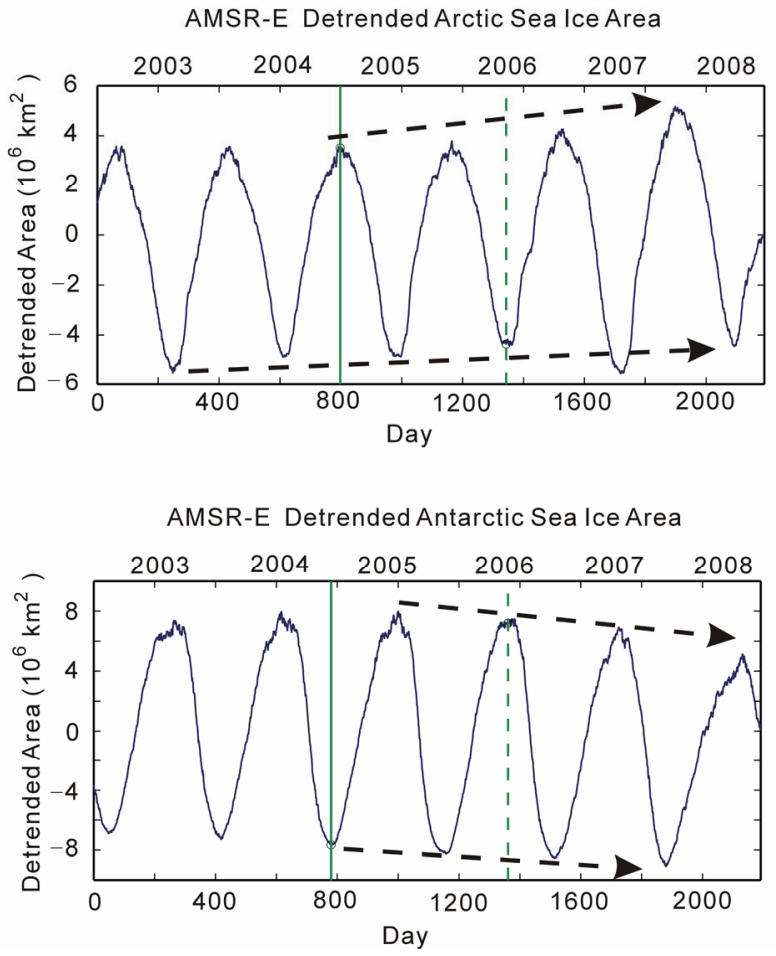

Figure 6. Detrended daily time series of Arctic (top) and Antarctic (bottom) sea ice area. Arrows indicate changes in the seasonal minima and maxima. Green lines are for visual reference of contrasting minima to maxima.

\section{CONCLUSIONS}

The satellite instrument retrievals of daily northern and southern hemisphere sea ice areas were investigated for secular trends and periodic variations. The daily retrievals derived from the SMMR-SSM/I NASA Team algorithm from 1979 through 2007 and the AMSR-E Institute of Oceanography - University of Hamburg algorithm from 2003 through 2008. Secular trends show a decrease in Arctic sea ice area and an increase Antarctic sea ice area over their respective time periods. Since 2003 the AMSR-E secular trends indicated accelerations of decreasing Arctic sea ice area, by a factor 18, and increasing Antarctic sea ice area, by a factor of 16 relative the SMMR-SSM/I secular trends, respectively. The Polar sea ice area, the daily sum of the northern and southern sea ice regions, showed an acceleration of increasing sea ice area, due to the increase in Antarctic sea ice area, since 2003 (AMSR-E) as well.

Spectral analysis of the daily sea ice areas showed the annual cycle to be 372.14 days, on average, for the SMMR-SSM/I and AMSR-E time series. The annual cycle varied from 305 days to 394 days. The recurrence interval of the annual cycle is about 61.7 years, on average. Significant spectral power occurred at from 4-day through 120-day frequencies, which were consistent with 
those of solar irradiation, Rossby waves, length-of- day and polar motion. These results suggest a linkage of the daily sea ice area variations in the northern and southern hemispheres with the 60-year solar - atmosphere length-of-day modulation. We hypothesize the spectral content of the daily Polar sea ice variations is a consequence of conservation of angular momentum, solar irradiation and ocean heat content variations.

The detrended daily AMSR-E Arctic sea ice area shows the Arctic seasonal maxima to be increasing, while the seasonal minima decreasing. The detrended daily AMSR-E Antarctic seasonal maxima show the seasonal minima decreasing, and the seasonal maxima decreasing. These findings suggest processes operating to moderate the long-term secular trends. If these processes continue as linked to the 60-year solar - atmosphere - length-of-day modulation, then the long- and short-term secular trends, decreasing Arctic seas ice area and increasing Antarctic sea ice area, are reversible within a range of 15 to 30 -years.

\section{ACKNOWLEDGEMENTS}

We thank the Arctic Region Supercomputing Center, University of Alaska Fairbanks for computing facilities support and the Japan Aerospace Exploration Agency for computing facilities support at the International Arctic Research Center. The National Snow and Ice Data Center, University of Colorado, The Polar Research Group, University of Illinois, Urbana-Champlain, USA, and the Institute of Oceanography, University of Hamburg, Germany are thanked. Prof. Syun-Ichi Akasofu is thanked for encouraging this work. This work was performed by R.R. Muskett at the International Arctic Research Center, University of Alaska Fairbanks, Alaska, USA.

\section{REFERENCES}

[1] Aagaard, K. and Carmack, E.C. (1989) The role of sea ice and other fresh water in the Arctic circulation. Journal of Geophysical Research, 94, 14485-14498. doi:10.1029/JC094iC10p14485

[2] Washington, W.M. (1992) Climate-model responses to increased $\mathrm{CO} 2$ and other greenhouse gases. In: Trenberth, K.E. Ed., Climate System Modeling, Cambridge University Press, Cambridge, 643-666.

[3] Curry, J.A. and Schramm, J.L. (1995) Sea ice-climate feedback mechanism. Journal of Climate, 8, 240-247. doi:10.1175/1520-0442(1995)008<0240:SIACFM $>2.0$.C $\mathrm{O} ; 2$

[4] Lemke, P., Harder, M. and Helmer, M. (2000) The response of Arctic sea ice to global change. Climatic Change, 46, 277-287. doi:10.1023/A:1005695109752

[5] Gorodetskaya, I.V., Cane, M.A., Tremblay, L.-B. and Kaplan, A. (2006) The effects of sea-ice and land-snow concentrations on planetary albedo from the earth radiation budget experiment. Atmosphere-Ocean, 44, 195-205. doi:10.3137/ao.440206

[6] Cavalieri, D.C., Gloersen, P., Parkinson, C.L., Comiso,
J.C. and Zwally, H.J. (1997) Observed hemispheric asymmetry in global sea ice changes. Science, 278, 1104-1106. doi:10.1126/science.278.5340.1104

[7] Cavalieri, D.J., Parkinson, C.L., Gloersen, P., Comiso, J.C. and Zwally, H.J. (1999) Deriving long-term time series of sea ice cover from satellite passive-microwave multisensor data sets. Journal of Geophysical Research, 104, 15803-15814. doi:10.1029/1999JC900081

[8] Zwally, H.J., Comiso, J.C., Parkinson, C.L., Cavalieri, D.J. and Gloersen, P. (2002) Variability of Antarctic sea ice 1979-1998. Journal of Geophysical Research, 107, 1-9. doi:10.1029/2000JC000733

[9] Cavalieri, D.J., Parkinson, C.L. and Vinnikov, K.Y. (2003) 30-year satellite record reveals contrasting Arctic and Antarctic decadal sea ice variability. Geophysical Research Letters, 30, 1-4. doi:10.1029/2003GL018031

[10] Cavalieri, D.J. and Parkinson, C.L. (2008) Antarctic sea ice variability and trends, 1979-2006. Journal of Geophysical Research, 113, Article ID C07004, 1-19.

[11] Spreen, G., Kaleschke, L. and Heygster, G. (2008) Sea ice remote sensing using AMSR-E 89-GHz channels. Journal of Geophysical Research, 113, Article ID C02S03, $1-14$.

[12] Zwally, H.J., Comiso, J.C., Parkinson, C.L., Campbell, W.J., Carsey, F.D. and Gloersen, P. (1983) Variability of Antarctic sea ice and changes in carbon dioxide. Science, 220, 1005-1012. doi:10.1126/science.220.4601.1005

[13] Comiso, J.C., Parkinson, C.L., Gersten, R. and Stock, L. (2008) Accelerated decline in the Arctic sea ice cover. Geophysical Research Letters, 35, Article ID L01703, 1-6.

[14] Overland, J., Turner, J., Francis, J., Gillett, N., Marshall, G. and Tjernstrom M. (2008) The Arctic and Antarctic: Two faces of climate change. Eos Transactions American Geophysical Union, 89, 177-179. doi:10.1029/2008EO190001

[15] Sullivan, R., Timmermann, A. and White, H. (2001) Dangers of data mining: The case of calendar effects in stock returns. Journal of Econometrics, 105, 249-286. doi:10.1016/S0304-4076(01)00077-X

[16] Cerveny, R.S., Svoma, B.M., Balling, R.C. Jr. and Vose, R.S. (2008) Gregorian calendar bias in monthly temperature databases. Geophysical Research Letters, 35, Article ID L19706, 1-4.

[17] Press, W.H., Teukolsky, S.A., Vetterling, W.T. and Flannery, B.P. (2007) Numerical recipes: The art of scientific computing. 3rd Edition, Cambridge University Press, Cambridge.

[18] Kukla, G. and Gavin, J. (1981) Summer sea ice and carbon dioxide. Science, 214, 497-503. doi: $10.1126 /$ science. 214.4520 .497

[19] Amemiya, T. and Wu, R.Y. (1972) The effect of aggregation on prediction in the autoregressive model. Journal of the American Statistical Association, 67, 628-632. doi: $10.2307 / 2284454$

[20] Wei, W.W.S. (1979) Some consequences of temporal aggregation in seasonal time series models. In: Zellner, A. Ed., Seasonal Analysis of Economic Time Series, National Bureau of Economic Research, Cambridge, 433-448.

[21] Box, G.E.P. and Jenkins, G.M. (1975) Time series analysis: Forecasting and control. Revised Edition, Holden- 
Day, San Francisco.

[22] Jenkins, G.M. and Watts, D.G. (1969) Spectral analysis and its applications. Emerson-Adams Press, Inc., Boca Raton.

[23] Bevington, B.R. and Robinson, D.K. (1992) Data reduction and error analysis for the physical sciences. 2nd Edition, McGraw-Hill, Inc., New York.

[24] Ahlquist, J.E. (1982) Normal-mode global Rossby waves: Theory and observations. Journal of the Atmospheric Sciences, 39, 193-202. doi:10.1175/1520-0469(1982)039<0193:NMGRWT>2.0. $\mathrm{CO} ; 2$

[25] Ahlquist, J.E. (1985) Climatology of normal-mode Rossby waves. Journal of the Atmospheric Sciences, 42, 2059-2068. doi:10.1175/1520-0469(1985)042<2059:CONMRW $>2.0$. $\mathrm{CO} ; 2$

[26] Duvall, T.L. Jr., Jones, H.P. and Harvey, J.W. (1983) Solar oscillations with 13-day period. Nature, 304, 517518. doi:10.1038/304517a0

[27] Pap, J., Tobiska, W.K. and Bouwer, S.D. (1990) Periodicities of solar irradiance and solar activities, I. Solar Physics, 129, 165-189. doi:10.1007/BF00154372

[28] Djurovic, D. and Pâquet, P. (1991) Variations common to the interplanetary magnetic field, the zonal atmospheric circulation and the earth's rotation. Quarterly Journal of the Royal Meteorological Society, 117, 571-586. doi:10.1002/qj.49711749908

[29] Bouwer, S.D. (1992) Periodicities of solar irradiance and solar activity indices, II. Solar Physics, 142, 365-389. doi:10.1007/BF00151460

[30] Zhou, S., Rottman, J. and Miller, A.J. (1997) Stratospheric ozone response to short-and intermediate-term variations of solar UV flux. Journal of Geophysical Research, 102, 9003-9011. doi:10.1029/96JD03383

[31] Nikonova, M.V., Klochek, N.V. and Palamarchuk, L.E. (1998) Quasi-10-day and 4-day periodicities in solar irradiance. In: F.L. Deubner, et al. Eds., New Eyes to See Inside the Sun and Stars, International Astronomical Union, Kyoto, 119-120.

[32] Renwick, J.A. and Revell, M.J. (1999) Blocking over the South Pacific and Rossby wave propagation. Monthly
Weather Review, 127, 2233-2247. doi:10.1175/1520-0493(1999)127<2233:BOTSPA $>2.0 . C$ $\underline{\mathrm{O} ; 2}$

[33] Baldwin, M.P. and Dunkerton, T.J. (2001) Stratospheric harbingers of anomalous weather regimes. Science, 294, 581-584. doi: $10.1126 /$ science. 1063315

[34] Cravatte, S., Boulanger, J.-P. and Picaut J. (2004) Reflection of intraseasonal equatorial Rossby waves at the western boundary of the Pacific Ocean. Geophysical Research Letters, 31, Article ID L10301, 1-4.

[35] Haldoupis, C., Pancheva, D. and Mitchell, N.J. (2004) A study of tidal and planetary wave periodicities present in midlatitude sporadic E layers. Journal of Geophysical Research, 109, Article ID A02302, 1-12.

[36] Geller, M.A. (2006) Discussion of the solar uv/planetary wave mechanism. Space Science Reviews, 125, 237-246. doi:10.1007/s11214-006-9060-7

[37] Soon, W.W.-H. (2005) Variable solar irradiance as a plausible agent for multidecadal variations in the Arctic-wide surface air temperature record of the past 130 years. Geophysical Research Letters, 32, Article ID L16712, 1-5.

[38] Mazzarella, A. (2007) The 60-year solar modulation of global air temperature: The Earth's rotation and atmospheric circulation connection. Theoretical and Applied Climatology, 88, 193-199. doi:10.1007/s00704-005-0219-z

[39] Barnes, R.T.H., Hide, R., White, A.A. and Wilson, C.A. (1983) Atmospheric angular momentum fluctuations, length-of-day changes and polar motion. Proceedings of the Royal Society A, 387, 31-73. doi:10.1098/rspa.1983.0050

[40] Ponte, R.M. (2002) Rapid ocean signals in polar motion and length of day. Geophysical Research Letters, 29, Article ID 151711, 1-4.

[41] Hibler, W.D. and Flato, G.M. (1992) Sea ice models. In: Trenberth K.E. Ed., Climate System Modeling, Cambridge University Press, Cambridge, 413-435.

[42] Cavalieri, D.J. and Häkkinen, S. (2001) Arctic climate and atmospheric planetary waves. Geophysical Research Letters, 28, 791-794. doi:10.1029/2000GL011855 